\title{
BULK MAGNETIC PROPERTIES OF NANOSIZED SPINEL FERRITES
}

\author{
Hina Bhargava1, K.T. Vasudevan ${ }^{2}$, N. Lakshmi ${ }^{3}$, K. Venugopalan ${ }^{4}$ \\ ${ }^{1}$ Associate Professor, Department of Physics, T John Institute of Technology, Bangalore, Karnataka, India \\ ${ }^{1}$ Corresponding Author: hinaoza@tjohngroup.com \\ ${ }^{2}$ Professor, Department of Physics, T John Institute of Technology, Bangalore, Karnataka, India \\ ${ }^{3}$ Professor, Department of Physics, Mohanlal Sukhadia University, Udaipur, Rajasthan, India \\ ${ }^{4}$ Professor, Department of Physics, Mohanlal Sukhadia University, Udaipur, Rajasthan, India
}

\begin{abstract}
Nanosized Co0.5Zn0.5Fe2O4 and $\mathrm{Cu} 0.5 \mathrm{ZnO} .5 \mathrm{Fe} 2 \mathrm{O} 4$ were prepared using Co-precipitation method. Using a combination of $x$ ray diffraction, Mössbauer studies and DC magnetization, the magnetic properties of nano sized CoO.5ZnO.5Fe2O4 and $\mathrm{Cu} 0.5 \mathrm{ZnO} 0.5 \mathrm{Fe} 2 \mathrm{O} 4$ have been studied. Although the preparation conditions were kept same, the particle size of $\mathrm{Cu} 0.5 \mathrm{ZnO} .5 \mathrm{Fe} 2 \mathrm{O} 4$ $(2.4 \mathrm{~nm})$ were smaller than that of $\mathrm{CoO} .5 \mathrm{ZnO} .5 \mathrm{Fe} 2 \mathrm{O} 4(5.8 \mathrm{~nm})$ as the formation of $\mathrm{CuO} 0.5 \mathrm{ZnO} 0.5 \mathrm{Fe} 2 \mathrm{O} 4$ is more exothermic in nature that the formation of $\mathrm{Co} 0.5 \mathrm{ZnO} .5 \mathrm{Fe} 2 \mathrm{O} 4$. The dependence of DC magnetization on particle size and cation distribution have been studied.
\end{abstract}

Keywords: Spinel ferrites, Co-precipitation, magnetic properties, Mössbauer spectroscopy

\section{INTRODUCTION:}

Magnetic ferrite materials have been intensively studied during the past few decades to understand fundamental phenomena as well as due to their technological importance. These materials are used in a numerous technological applications such as high density magnetic storage devices, electronic communication devices, targeted drug delivery, sensors, magnetic printing inks, applications in ferrofluid technology, magnetic refrigeration, catalysts and in magnetic resonance imaging enhancement [1]. The magnetic properties of these systems are not only because of the cation distribution in different sites but also due to the reduced size of the magnetic particle [2].For this reason, various methods such as the ceramic method, sol gel, coprecipitation, solvent evaporation, hydrothermal, combustion, microemulsion and precursor methods have been reported in literature for the preparation of these nanoscale spinel ferrites [3].

The coprecipitation method is widely used for the preparation of ferrites [4] because it is economical and time saving and has overriding advantages such as the ease of controlling the composition, homogeneity, ability to be processed at lower temperatures and superior properties.

The aim of the present work is to investigate the structural and magnetic properties of $\mathrm{Co}_{0.5} \mathrm{Zn}_{0.5} \mathrm{Fe}_{2} \mathrm{O}_{4}$ and $\mathrm{Cu}_{0.5} \mathrm{Zn}_{0.5} \mathrm{Fe}_{2} \mathrm{O}_{4}$ prepared by chemical co-precipitation method.

\subsection{Experimental:}

The nano particles of $\mathrm{Co}_{0.5} \mathrm{Zn}_{0.5} \mathrm{Fe}_{2} \mathrm{O}_{4}$ and $\mathrm{Cu}_{0.5} \mathrm{Zn}_{0.5} \mathrm{Fe}_{2} \mathrm{O}_{4}$ were prepared by chemical co-precipitation method at $333 \mathrm{~K}$. For this purpose A.R. grade $\mathrm{CuCl}_{2} \cdot 2 \mathrm{H}_{2} \mathrm{O}, \mathrm{CoCl}_{2} \cdot 6 \mathrm{H}_{2} \mathrm{O}$, $\mathrm{ZnCl}_{2}$, and $\mathrm{Fe}\left(\mathrm{NO}_{3}\right)_{3} \cdot 2 \mathrm{H}_{2} \mathrm{O}$ were weighed in stoichiometric ratios then were mixed then dissolved in water, maintained at temperatures $333 \mathrm{~K}$. To maintain $\mathrm{pH}$ value $10,25 \%$ solution of $\mathrm{NH}_{4} \mathrm{OH}$ was added to the prepared solution. For the complete precipitation the solution was continuously stirred, at a constant temperature of $333 \mathrm{~K}$ for $2 \mathrm{hrs}$. The precipitate was then washed and dried at $373 \mathrm{~K}$ for 24 hours. Nano sized samples were prepared by annealing the dried samples at $573 \mathrm{~K}$ for 24 hours.

X-ray diffraction (XRD) spectra was obtained for structural characterization and determination of the average sizes of nano sized samples. Rigaku-Miniflex X-ray diffractometer with $\mathrm{Cu}-\mathrm{K} \alpha$ radiation was used for the same. A standard Austin drive and controller assembly, in the constant acceleration mode were used to record Mössbauer spectra. $12 \mathrm{mCi}{ }^{57} \mathrm{Co}$ in Rhodium matrix was used as Mössbauer source and velocity calibration was done using metallic iron foil. Magnetic measurements were done using a 7300 vibrating sample magnetometer (VSM). The blocking temperatures $\left(T_{B}\right)$ of nano sized samples were determined by plotting $M$ vs. $T$, where $M$ is the magnetic moment and $T$ is the temperature from the zero field cooled (ZFC) curves over a temperature range of $20 \mathrm{~K}$ to $300 \mathrm{~K}$. A small DC field of 50 Oe was used for FC-ZFC measurements.

\subsection{Results And Discussion:}

1. X-Ray Analysis:

$\mathrm{X}$-ray spectra of $\mathrm{Co}_{0.5} \mathrm{Zn}_{0.5} \mathrm{Fe}_{2} \mathrm{O}_{4}$ and $\mathrm{Cu}_{0.5} \mathrm{Zn}_{0.5} \mathrm{Fe}_{2} \mathrm{O}_{4}$ annealed at $300^{\circ} \mathrm{C}$ is shown in Figure 1 . From the $\mathrm{X}$-ray spectra it is evident that both the samples have single phased spinel structure. The increase in the broadening of most intense peak (311) shows decrease in the particle size with the replacement of $\mathrm{Co}$ by $\mathrm{Cu}$ [Table 1]. Average particle size for the prepared samples is calculated using Scherrer formula [Table 1]: 
Particle Size $=\frac{0.9 \lambda}{B \operatorname{Cos} \theta}$

Where $\lambda$ is wavelength of $\mathrm{X}$ rays, and $B$ corresponds to the width of most intense peak in the XRD spectrum.

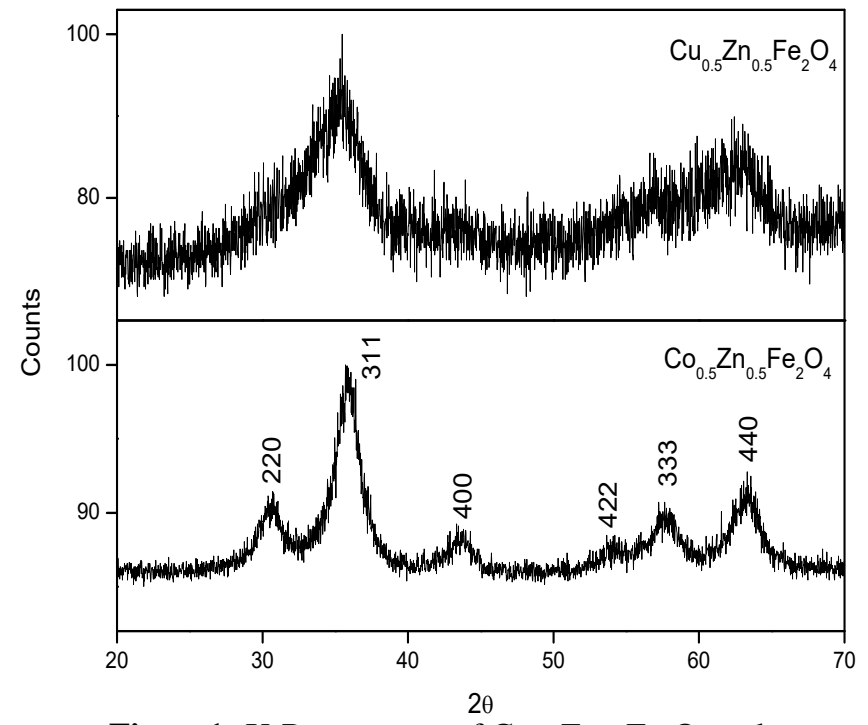

Figure1: $\mathrm{X}$-Ray spectra of $\mathrm{Co}_{0.5} \mathrm{Zn}_{0.5} \mathrm{Fe}_{2} \mathrm{O}_{4}$ and $\mathrm{Cu}_{0.5} \mathrm{Zn}_{0.5} \mathrm{Fe}_{2} \mathrm{O}_{4}$ annealed at $573 \mathrm{~K}$.

In co-precipitation method, the crystal growth is highly influenced by molecular concentration of the material approaching the surface during the process. The temperature at the particle surface become higher than the solution temperature due to liberation of latent heat at the surface which results in the obstruction of crystal growth [4]. It suggest that the formation of $\mathrm{Cu}-\mathrm{Zn}$ ferrite is more exothermic as compared to the formation of $\mathrm{Co}-\mathrm{Zn}$ ferrite.

The values of lattice constants of the samples calculated from the peak positions are given in Table 1. The lattice constant of $\mathrm{Cu}_{0.5} \mathrm{Zn}_{0.5} \mathrm{Fe}_{2} \mathrm{O}_{4}$ is more compared to that of $\mathrm{Co}_{0.5} \mathrm{Zn}_{0.5} \mathrm{Fe}_{2} \mathrm{O}_{4}$. The reason for the increase in the lattice constant with decrease in particle size can be understood as follows. As the particle size is reduced, the surface to volume ratio increases, the excess free energy associated with the surface increases the total free energy of the particle. A small particle can reduce this excess free energy by altering its lattice structure in an appropriatemanner. This reduction in the excess free energy is accompanied by the expansion of the lattice to an energetically less favorable crystallographic structure; however, the overall energetics increases the stability [5].

Table 1: Structural parameters for prepared samples

\begin{tabular}{|l|c|c|}
\hline Sample & $\begin{array}{l}\text { Particle Size } \\
(\mathrm{nm})\end{array}$ & $\begin{array}{l}\text { Lattice } \\
\text { Parameter }(\AA)\end{array}$ \\
\hline $\mathrm{Co}_{0.5} \mathrm{Zn}_{0.5} \mathrm{Fe}_{2} \mathrm{O}_{4}$ & 5.8 & 8.28 \\
\hline $\mathrm{Cu}_{0.5} \mathrm{Zn}_{0.5} \mathrm{Fe}_{2} \mathrm{O}_{4}$ & 2.4 & 8.49 \\
\hline
\end{tabular}

\section{ROOM TEMPERATURE MÖSSBAUER STUDIES:}

Mössbauer spectroscopy is a potent technique to characterize superparamagnetic nanoparticles. For nanoparticles with uniaxial anisotropy, the energy barrier, between the two easy directions of magnetization is smaller than the thermal energy even at the room temperature. This leads to the spontaneous fluctuation of the magnetization direction, having relaxation time given by [6],

$$
\tau=\tau_{0} \exp \left(\frac{K V}{k_{B} T}\right)
$$

Where $v_{0}\left(10^{-9}-10^{-10} \mathrm{~s}\right)$ is the inverse of the natural frequency of the gyromagnetic precession, $\mathrm{K}$ is the anisotropy constant, $\mathrm{V}$ is the volume of the particle, $\mathrm{k}_{\mathrm{B}}$ is the Boltzmann constant and $\mathrm{T}$ is the temperature (in Kelvin).

The superparamagnetic relaxation of the single domain magnetic nanoparticle can be observed by a technique with characteristic time $\left(\mathrm{l}_{\mathrm{s}}\right)$ at the temperature above the so called blocking temperature $\left(\mathrm{T}_{\mathrm{B}}\right)$ defined by,

$$
T_{B}=\frac{K V}{k_{B} \ln \left(\frac{\tau_{S}}{\tau_{0}}\right)}
$$

Above the blocking temperature, the relaxation time $1<<\mathbf{1}_{\mathrm{s}}(\sim$ $10^{-8} \mathrm{~s}$ for the Mössbauer spectroscopy) and the internal magnetic field is averaged out giving rise to a quadrupolar doublet in the Mössbauer pattern. [7].

Room temperature Mössbauer spectra have been recorded for the samples $\mathrm{Co}_{0.5} \mathrm{Zn}_{0.5} \mathrm{Fe}_{2} \mathrm{O}_{4}$ and $\mathrm{Cu}_{0.5} \mathrm{Zn}_{0.5} \mathrm{Fe}_{2} \mathrm{O}_{4}$ (Figure 2 show Mössbauer spectra for samples annealed at $573 \mathrm{~K}$ ). The obtained hyperfine parameters are tabulated in Table 2. For both the samples Mössbauer spectra shows clear doublets at the central region with no signature of sextet. Mössbauer spectra for samples $\mathrm{Co}_{0.5} \mathrm{Zn}_{0.5} \mathrm{Fe}_{2} \mathrm{O}_{4}$ and $\mathrm{Cu}_{0.5} \mathrm{Zn}_{0.5} \mathrm{Fe}_{2} \mathrm{O}_{4}$ annealed at $573 \mathrm{~K}$ have been fitted with two doublets corresponding to $\mathrm{A}$ and $\mathrm{B}$ sites. This indicates that these samples are superparamagnetic at room temperature.

The isomer shift have been quoted with respect to metallic Fe. Observed Isomer shifts (Table 2) of these samples confirm the presence of only $\mathrm{Fe}^{3+}$ ions in the samples. Due to the presence of large covalancy at A site, the isomer shift of A site is usually smaller than that of B site [8]. Observed isomer shift for $\mathrm{A}$ and $\mathrm{B}$ site in these samples are approximately same (Table 2). This advocates the same nature of bonds present at $\mathrm{A}$ and $\mathrm{B}$ site respectively. The QS values of doublets (for samples $\mathrm{Co}_{0.5} \mathrm{Zn}_{0.5} \mathrm{Fe}_{2} \mathrm{O}_{4}$ and $\left.\mathrm{Cu}_{0.5} \mathrm{Zn}_{0.5} \mathrm{Fe}_{2} \mathrm{O}_{4}\right)$ indicate the significant electric field gradient (EFG) around the ${ }^{57} \mathrm{Fe}$ nuclei. Large EFG in the samples $\mathrm{Co}_{0.5} \mathrm{Zn}_{0.5} \mathrm{Fe}_{2} \mathrm{O}_{4}$ and $\mathrm{Cu}_{0.5} \mathrm{Zn}_{0.5} \mathrm{Fe}_{2} \mathrm{O}_{4}$, can be attributed to the large surface to volume ratio in [9]. 
Table 2: RT Mössbauer Parameters:

\begin{tabular}{|l|c|c|c|c|}
\hline \multirow{2}{*}{ Sample } & \multicolumn{3}{|l|}{$\begin{array}{l}\text { Isomer Shift } \\
(\mathrm{mm} / \mathrm{s})\end{array}$} & \multicolumn{2}{l|}{$\begin{array}{l}\text { Quadrupole } \\
\text { Splitting } \\
(\mathrm{mm} / \mathrm{s})\end{array}$} \\
\cline { 2 - 5 } & A Site & B Site & A Site & B Site \\
\hline $\mathrm{Co}_{0.5} \mathrm{Zn}_{0.5} \mathrm{Fe}_{2} \mathrm{O}_{4}$ & 0.339 & 0.345 & 0.503 & 0.7863 \\
\hline $\mathrm{Cu}_{0.5} \mathrm{Zn}_{0.5} \mathrm{Fe}_{2} \mathrm{O}_{4}$ & 0.348 & 0.356 & 0.521 & 0.870 \\
\hline
\end{tabular}

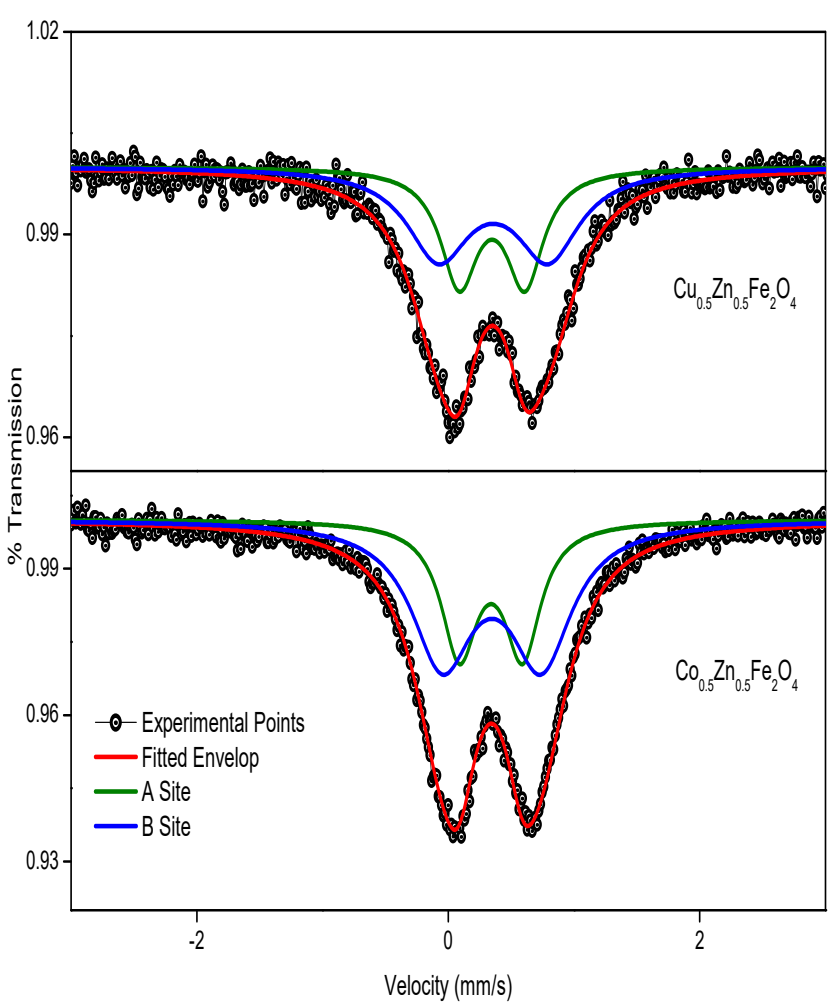

Figure 2: Room temperature Mössbauer spectra for samples $\mathrm{Co}_{0.5} \mathrm{Zn}_{0.5} \mathrm{Fe}_{2} \mathrm{O}_{4}$ and $\mathrm{Cu}_{0.5} \mathrm{Zn}_{0.5} \mathrm{Fe}_{2} \mathrm{O}_{4}$ annealed at $573 \mathrm{~K}$.

\section{DC MAGNETIZATION:}

The field dependent magnetization (M-H curve) of $\mathrm{Co}_{0.5} \mathrm{Zn}_{0.5} \mathrm{Fe}_{2} \mathrm{O}_{4}$ and $\mathrm{Cu}_{0.5} \mathrm{Zn}_{0.5} \mathrm{Fe}_{2} \mathrm{O}_{4}$, annealed $573 \mathrm{~K}$ are shown in Figure. 3. M-H curves for the samples show reversible behavior (Figure 3). This reversible behavior parades the superparamagnetic nature of these samples. Saturation magnetization $M_{S}$ of the samples $\mathrm{Co}_{0.5} \mathrm{Zn}_{0.5} \mathrm{Fe}_{2} \mathrm{O}_{4}$ and $\mathrm{Cu}_{0.5} \mathrm{Zn}_{0.5} \mathrm{Fe}_{2} \mathrm{O}_{4}$ is assessed by plotting $M \mathrm{Vs} 1 / H$ for $1 / H$ tends to zero. From Table 3 it can be observed that the saturation magnetization decreases with the decrease in the particle size. As the particle size decreases, the surface to volume ratio increases which endorses the increase of magnetically dead layer which is responsible for the decrease in the saturation magnetization[10].

The magnetic order in spinel ferrites is due to the indirect superexchange interaction between the metal ions in the tetrahedral A sites and octahedral B site. The net magnetization in spinel ferrites is proportional to the difference between magnetic moment of tetrahedral (A) and octahedral (B) sites $\left(M_{S}=M_{B}-M_{A}\right)$ which implies the strong dependence of $M_{S}$ on cation distribution [11].

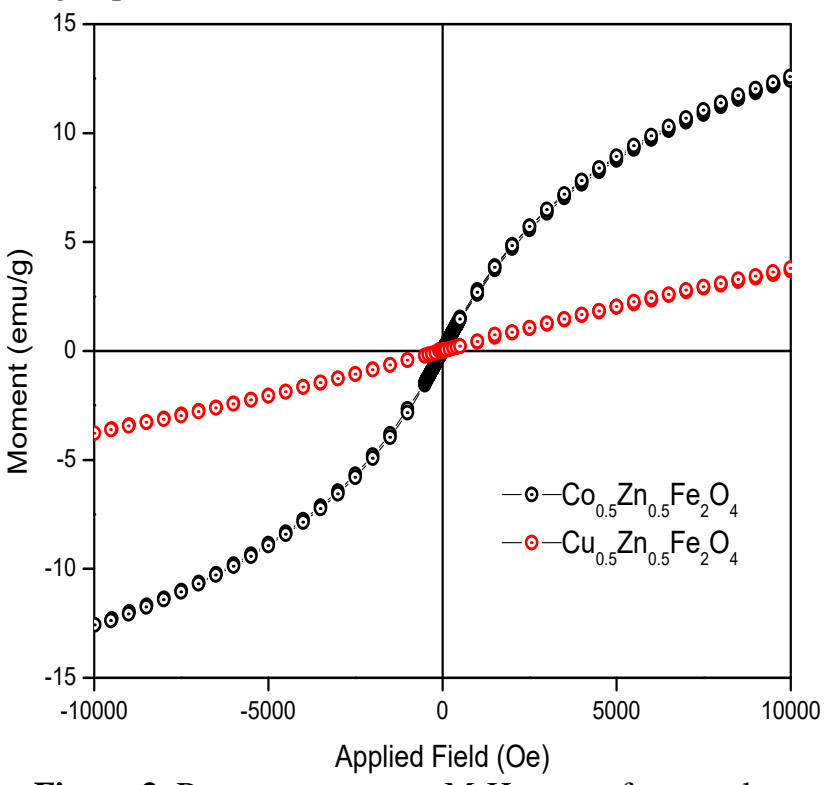

Figure 3: Room temperature $\mathrm{M}-\mathrm{H}$ curves for samples $\mathrm{Co}_{0.5} \mathrm{Zn}_{0.5} \mathrm{Fe}_{2} \mathrm{O}_{4}$ and $\mathrm{Cu}_{0.5} \mathrm{Zn}_{0.5} \mathrm{Fe}_{2} \mathrm{O}_{4}$ annealed at $573 \mathrm{~K}$.

Table 3: DC Magnetization Parameters

\begin{tabular}{|l|l|l|l|l|}
\hline Sample & $\begin{array}{l}\text { Saturation Magnetization } \\
(\mathrm{emu} / \mathrm{g})\end{array}$ & $\begin{array}{l}\text { Blocking Temperature } \\
(\mathrm{K})\end{array}$ & $\begin{array}{l}\text { Tirr } \\
(\mathrm{K})\end{array}$ & $\begin{array}{l}\text { Anisotropy Constant } \\
(\mathrm{erg} / \mathrm{K})\end{array}$ \\
\hline $\mathrm{Co}_{0.5} \mathrm{Zn}_{0.5} \mathrm{Fe}_{2} \mathrm{O}_{4}$ & 15.5 & 149 & 169 & $7.0 \times 10^{5}$ \\
\hline $\mathrm{Cu}_{0.5} \mathrm{Zn}_{0.5} \mathrm{Fe}_{2} \mathrm{O}_{4}$ & 7 & 57 & 57 & $1.89 \times 10^{6}$ \\
\hline
\end{tabular}

It is clear from the literature that $\mathrm{Co}^{2+}$ and $\mathrm{Cu}^{2+}$ both have strong $\mathrm{B}$ site preference. When nonmagnetic $\mathrm{Cu}^{2+}$ ion is substitutedinstead of magnetic $\mathrm{Co}^{2+}$ ion, the magnetization at $\mathrm{B}$ site decreases, which reduces the net saturation magnetization. To determine blocking temperature $\left(T_{B}\right)$ of the superparamagnetic material Field cooled-zero field cooled M-T measurements are used. For Zero field cooling (ZFC) at first the sample is cooled from room temperature, in zero magnetic field. The small magnetic field is applied and magnetic moment $\left(\mathrm{M}_{\mathrm{ZFC}}\right)$ is recorded during the heating 
cycle. For Field cooled M-T measurement the same process is repeated with the application of small magnetic field during the cooling cycle also (same magnetic field is applied for the warming cycle of ZFC and cooling/warming cycles of FC). The maxima obtained in ZFC curves provide the blocking temperature $\left(\mathrm{T}_{\mathrm{B}}\right)$ of the prepared samples [Table 3].From figure it is evident that the blocking temperature of $\mathrm{Co}_{0.5} \mathrm{Zn}_{0.5} \mathrm{Fe}_{2} \mathrm{O}_{4}$ is higher than that of $\mathrm{Cu}_{0.5} \mathrm{Zn}_{0.5} \mathrm{Fe}_{2} \mathrm{O}_{4}$. According to the following equation

$$
T_{B}=\frac{K V}{25 k_{B}}
$$

where, $\mathrm{K}$ is the effective anisotropy constant, $\mathrm{V}$ the volume and $\mathrm{k}_{\mathrm{B}}$ the Boltzmann constant, it is apparent that, $\mathrm{T}_{\mathrm{B}}$ is directly proportional to the volume of nano particles, suggesting that larger sized particles will have larger $T_{B}$ [12].



Figure 4: FC-ZFC measurement for the samples $\mathrm{Co}_{0.5} \mathrm{Zn}_{0.5} \mathrm{Fe}_{2} \mathrm{O}_{4}$ and $\mathrm{Cu}_{0.5} \mathrm{Zn}_{0.5} \mathrm{Fe}_{2} \mathrm{O}_{4}$ annealed at $573 \mathrm{~K}$.

The anisotropy is affected by the presence of magnetically dead layer on the surface of the nano particle. The effective anisotropy is given by the following equation:

$$
K_{e f f}=K+K_{S}+K_{s h}+K_{i n}
$$

Where $K$ is the magnetocrystalline anisotropy, $K_{S}$ is a surface anisotropy constant, $K_{s h}$ is shape anisotropy constant, and $K_{i n}$ is the constant of supplementary anisotropy present in the sample due to the presence of nanocrystalline interactions [13]. The contribution of surface anisotropy to $K_{\text {eff }}$ increases due to the increase in the surface magnetically dead layer which results in an increase in the effective anisotropy constant $K_{\text {eff }}$ with decreasing particle size.

\section{CONCLUSION:}

In summary, nano sized samples of $\mathrm{Co}_{0.5} \mathrm{Zn}_{0.5} \mathrm{Fe}_{2} \mathrm{O}_{4}$ and $\mathrm{Cu}_{0.5} \mathrm{Zn}_{0.5} \mathrm{Fe}_{2} \mathrm{O}_{4}$ were synthesized by chemical coprecipitation method. The magnetic properties of nano sized ferrite particle are highly dependent on cation distribution and also on particle size.

\section{REFERENCES:}

[1]. M. Raghasudha, D. Ravinder, P Veerasomaiah, JMMM 355,( 2014), 210-214

[2]. Z. Karimi, Y. Mohammadifar, H. Shokrollahi, Sh. Khameneh Asl, Gh. Yousefi, L. KarimiJMMM 361, (2014), 150-156

[3]. M.A. Gabal,Mat. Lett. 64, (2010), 1887-1890

[4]. Munish Gupta, Manik Gupta, B.S. RandhawaJ. All. Comp., 626(2015), 421-427

[5]. Hina Bhargava, V. D. Sudheesh, J. Nehra, Varkey Sebastian, N. Lakshmi , K. Venugopalan, V. R. Reddy, Ajay Gupta. Bull. Mat. Sci., 37 (2014), 953-961

[6]. Hina Bhargava, N. Lakshmi , Ram Kripal Sharma, K. Venugopalan, Hyp.Int., 183 (2008), 155-161

[7]. C. M. Srivastava, S. N. Shringi, and R. G. Srivastava, Phys. Rev. B 14(1976),

[8]. Woo Chul Kim, Sam Jin Kim, Young Rang Uhm, and Chul Sung Ki IEEE TRANS. ON MAG., 37( 2001),2362

[9]. L. Wang', F.S. Li,JMMM223( 2001), 233-237

[10].N.S. Gajbhiye, G. Balaji and M. Ghafari Phys.Stat. sol. (a) 189,(2002) 357-361,

[11].Kush Rana, Preeti Thakur, Parul Sharma, M. Tomar, V. Gupta, Atul Thakur,Ceramics International, 41(2015), 4492-4497

[12].Yüksel Köseoğlu ${ }^{\mathrm{a},}$, , Furkan Alan ${ }^{\mathrm{a}}$, Muhammed Tan ${ }^{\mathrm{a}}$, Resul Yilgin ${ }^{\mathrm{b}}$, Mustafa Öztürk ${ }^{\mathrm{b}}$ Ceramics International, 38 (2012), 3625-3634

[13].C Caizerand M StefanescuJ. Phy. D: App. Phy. 35 (2002), 3035 